\title{
Effects of dietary amines on the gut and its vasculature
}

\author{
Kenneth J. Broadley*, M. Akhtar Anwar, Amy A. Herbert, Martina Fehler, Elen M. Jones, Wyn E. Davies, \\ Emma J. Kidd and William R. Ford \\ Division of Pharmacology, Welsh School of Pharmacy, Cardiff University, King Edward VII Avenue, Cathays Park, Cardiff CF10 \\ $3 N B, U K$
}

(Received 7 July 2008 - Revised 29 August 2008 - Accepted 18 September 2008 - First published online 19 November 2008)

Trace amines, including tyramine and $\beta$-phenylethylamine ( $\beta$-PEA), are constituents of many foods including chocolate, cheeses and wines and are generated by so-called 'friendly' bacteria such as Lactobacillus, Lactococcus and Enterococcus species, which are found in probiotics. We therefore examined whether these dietary amines could exert pharmacological effects on the gut and its vasculature. In the present study we examined the effects of tyramine and $\beta$-PEA on the contractile activity of guinea-pig and rat ileum and upon the isolated mesenteric vasculature and other blood vessels. Traditionally, these amines are regarded as sympathomimetic amines, exerting effects through the release of noradrenaline from sympathetic nerve endings, which should relax the gut. A secondary aim was therefore to confirm this mechanism of action. However, contractile effects were observed in the gut and these were independent of noradrenaline, acetylcholine, histamine and serotonin receptors. They were therefore probably due to the recently described trace amine-associated receptors. These amines relaxed the mesenteric vasculature. In contrast, the aorta and coronary arteries were constricted, a response that was also independent of a sympathomimetic action. From these results, we propose that after ingestion, trace amines could stimulate the gut and improve intestinal blood flow. Restriction of blood flow elsewhere diverts blood to the gut to aid digestion. Thus, trace amines in the diet may promote the digestive process through stimulation of the gut and improved gastrointestinal circulation.

Dietary trace amines: Gut contractile activity: Vascular activity: Mesenteric bed

Trace amines, including tyramine and $\beta$-phenylethylamine $(\beta-P E A)$, are biologically active amines occurring in the body in trace amounts. They are also found in the diet, derived from plants, bacteria and fungi ${ }^{(1)}$. Foods rich in tyramine and $\beta$-PEA include cheeses, red wine, fermented foods, such as sausages, and cocoa-containing foods, such as chocolate ${ }^{(2)}$. The recently popularised probiotic foods owe their reputed beneficial effects on health to high levels of lactic acid-producing bacteria such as Lactobacillus, Lactococcus and Enterococcus species. These are said to be 'friendly' bacteria, displacing harmful bacteria of the gut flora ${ }^{(3)}$ and combating infectious diarrhoea $^{(4)}$. Their commercial promotion is also based on a perceived ability to alleviate bloating and abdominal distension $^{(5)}$. Indeed, there is clinical evidence that bloating ${ }^{(6)}$ and flatulence ${ }^{(7,8)}$ associated with irritable bowel syndrome are reduced by probiotic bacterial supplements. It is not generally recognised, however, that the bacterial populations present in probiotic foods generate considerable levels of tyramine and $\beta-\operatorname{PEA}^{(9)}$.

Since trace amines are abundant in many foods and in drinks taken before or after meals (aperitifs, chocolates) ${ }^{(2)}$, in the present study we determined their effects on the gut and its vasculature. We examined the pharmacological effects of tyramine and $\beta$-PEA in isolated sections of gut from the guinea-pig or rat ileum which were electrically stimulated to simulate peristalsis. We also examined their effects on the mesenteric vasculature as an index of effects on blood flow to the gut, using rat isolated perfused mesenteric beds and compared these with the aorta and coronary vasculature.

Trace amines, such as tyramine and $\beta$-PEA, are classically regarded as having indirect sympathomimetic activity ${ }^{(10)}$. However, our recent studies have demonstrated a vasoconstriction by related amines that is independent of indirect sympathomimetic activity ${ }^{(11-13)}$. This raises the possibility that trace amines can also exert physiological effects through other receptors, such as the recently cloned trace amine-associated (TAA) receptors ${ }^{(14-17)}$. Thus, a secondary aim of the present study was to examine whether the effects of tyramine and $\beta$-PEA on the gut and its vasculature were mediated through sympathomimetic-dependent or -independent mechanisms.

\section{Experimental methods}

\section{Isolated ileum}

Male Sprague-Dawley rats (250-300g; Harlan, Bicester, Oxon, UK) or Dunkin-Hartley guinea-pigs (250-400 g; Harlan) were killed by cervical dislocation and exsanguination.

Abbreviations: CRC, concentration-response curve; $\mathrm{EC}_{30}$, molar concentration for $30 \%$ of maximal response; $\mathrm{EC}_{50}$, molar concentration for $50 \%$ of maximal response; 5-HT, 5-hydroxytryptamine; $\beta$-PEA, $\beta$-phenylethylamine; TAA, trace amine-associated.

* Corresponding author: Professor Kenneth J. Broadley, fax +44 2920 874149, email broadleykj@cardiff.ac.uk 
The guidelines for the care and use of laboratory animals were followed according to the Animals (Scientific Procedures) Act 1986.

Sections $(2 \mathrm{~cm})$ of ileum were isolated from rats or guineapigs and set up in tissue baths containing Krebs bicarbonate buffer $\left(\mathrm{pH} \mathrm{7.4)}\right.$ at $37^{\circ} \mathrm{C}$ gassed with $5 \% \mathrm{CO}_{2}$ in $\mathrm{O}_{2}$. The Krebs bicarbonate buffer was made up in distilled water and had the following composition (mM): $\mathrm{NaCl}, 100 ; \mathrm{NaHCO}_{3}$, 20; glucose, $10 ; \mathrm{MgSO}_{4} \cdot 7 \mathrm{H}_{2} \mathrm{O}, 1 ; \mathrm{KH}_{2} \mathrm{PO}_{4}, 1 ; \mathrm{KCl}, 5$; $\mathrm{CaCl}_{2} \cdot 2 \mathrm{H}_{2} \mathrm{O}$, 3. To simulate peristalsis, tissues were electrically stimulated with square-wave pulses $(0 \cdot 1 \mathrm{~Hz}, 5 \mathrm{~ms}$ pulse width, $10 \mathrm{~V})$ via parallel platinum electrodes located inside and outside the lumen. Isometric tension was measured by force transducers (Dynamometer UF1, $57 \mathrm{~g}$ sensitivity range; Pioden Controls Ltd, Canterbury, Kent, UK) coupled to a PowerLab/4SP computerised data acquisition system (ADInstruments, Charlgrove, Oxon, UK). Data were analysed using Chart version 4.1.1 software (ADInstruments). $\beta$-PEA or tyramine was added cumulatively in half-logarithmic increments in molar concentration to the tissue baths until the maximum effect was achieved.

\section{Mesenteric bed}

Male Sprague-Dawley rats (250-300 g) were killed by cervical dislocation and exsanguination. The superior mesenteric artery was cannulated and the mesenteric arterial bed excised and placed in a perfusion chamber. The bed was perfused at a constant flow rate $(4 \mathrm{ml} / \mathrm{min})$ with Krebs bicarbonate solution, warmed to $37^{\circ} \mathrm{C}$ and gassed with $95 \% \quad \mathrm{O}_{2}-5 \% \quad \mathrm{CO}_{2}$. Perfusion pressure was monitored by means of a pressure transducer (Elcomatic EM 750; Elcomatic Ltd, Glasgow, UK) connected to a computer data acquisition system (ADInstruments PowerLab, Chart 5). Increasing bolus doses (100 $\mu \mathrm{l})$ of $\beta$-PEA or tryramine were injected, each dose added after recovery of the response to the previous dose.

\section{Aortic ring preparations}

Rings $(3 \mathrm{~mm})$ were cut from the thoracic or abdominal aorta of male Sprague-Dawley rats $(250-300 \mathrm{~g})$ or Dunkin-Hartley guinea-pigs (250-400 g) and passed over fixed and mobile hooks. The latter was connected to an isometric transducer (Dynamometer UF1, $57 \mathrm{~g}$ sensitivity range; Pioden Controls Ltd, Canterbury, Kent, UK), a resting tension of $1.5 \mathrm{~g}$ applied and tension recorded on a computerised data acquisition system (ADInstruments PowerLab, Chart 5). Tissues were bathed in Krebs bicarbonate buffer $\left(37^{\circ} \mathrm{C}\right)$ gassed with $95 \%$ $\mathrm{O}_{2}-5 \% \mathrm{CO}_{2}$. Endothelium was removed by rolling the ring around a wooden cocktail stick. Endothelium denuding was confirmed by failure of acetylcholine $(100 \mu \mathrm{M})$ to relax aortae pre-contracted with the selective thromboxane $\mathrm{A}_{2}$ agonist, U46619 (9,11-dideoxy-9 $\alpha, 11 \alpha$-epoxymethanoprostaglandin $\left.\mathrm{F}_{2 \alpha} ; 1 \mu \mathrm{M}\right)$. After $1 \mathrm{~h}$ equilibration, isotonic $\mathrm{KCl}$ $(60 \mathrm{mM})$ was added to contract the tissue to test for tissue viability and as a standardisation response. After washout, noncumulative concentration-response curves (CRC) for $\beta$-PEA or tyramine were constructed by adding successive concentrations in half-logarithmic increments with washout between each. CRC were obtained either in the absence or presence of the inhibitors, prazosin $(1 \mu \mathrm{M})$, ICI-118,551 $(1 \mu \mathrm{M})$, cocaine
$(10 \mu \mathrm{M})$ and pargyline $(10 \mu \mathrm{M})$, which were incubated with the tissue for 15 min before commencing the CRC.

\section{Pig coronary artery rings}

Left anterior descending coronary arteries were dissected from porcine (either sex) hearts after transport at $4^{\circ} \mathrm{C}$ from the abattoir. Rings ( $5 \mathrm{~mm}$ long) were mounted in tissue baths and isometric tension recorded as described for aortic rings. Tissue viability was initially determined by contracting with $60 \mathrm{~mm}-\mathrm{KCl}$. After washout, intact endothelium was confirmed by at least $70 \%$ relaxation to $10 \mu \mathrm{M}$-bradykinin in rings precontracted with U46619 (5 nM). Acetylcholine contracts rather than relaxes pig coronary arteries ${ }^{(13,18)}$ and is therefore unsuitable for testing for the presence of endothelium and endothelium-derived relaxation. Baseline tensions were re-established by washing before obtaining a cumulative $\mathrm{CRC}$ to tyramine or $\beta$-PEA.

\section{Measurement of responses and analysis of results}

In isolated ileum preparations, increases in the baseline contractions to $\beta$-PEA or tyramine were plotted as a percentage of the maximum response to methacholine (acetyl- $\beta$-methylcholine) added at the start of the experiment or as a percentage of the maximum contractile response.

Responses of the mesenteric vascular bed were measured as the peak fall in perfusion pressure after each dose of tyramine or $\beta$-PEA and plotted as a percentage of the constriction by phenylephrine. Constrictions of aortic and coronary artery ring preparations above baseline were measured at the peak response to each concentration of $\beta$-PEA or tyramine and expressed as a percentage of the contraction to $\mathrm{KCl}(60 \mathrm{~mm})$ added at the beginning of an experiment. CRC for the mean responses with their standard errors were plotted against log molar concentration.

Geometric mean $\mathrm{EC}_{50}$ values (molar concentration for $50 \%$ of maximal response) and their $95 \%$ CI were calculated. To enable comparisons with a standard contractile agent in the ileum, responses were also expressed as a percentage of the maximum response to methacholine; because the maximum did not always reach $50 \%$ of the methacholine maximum, the $\mathrm{EC}_{30}$ values (molar concentration for $30 \%$ of the maximum response to methacholine) were calculated. $\mathrm{EC}_{30}$ and $\mathrm{EC}_{50}$ values and maximum responses expressed as a percentage of methacholine (ileum) or $\mathrm{KCl}$ contractions (aorta and coronary artery) were compared by Student's $t$ test for paired or unpaired two-set data or by ANOVA followed by post hoc Bonferroni's tests for multiple comparisons. $P<0.05$ was deemed significant.

\section{Materials}

The following drugs were used: acetylcholine chloride, atropine sulfate, bradykinin triacetate, cocaine hydrochloride, 5-hydroxy tryptamine (5-HT) hydrochloride (serotonin), methacholine (acetyl$\beta$-methylcholine) chloride, pargyline hydrochloride, (R)-(-)phenylephrine hydrochloride, 2-phenylethylamine hydrochloride ( $\beta$-phenylethylamine), ( \pm )-propranolol hydrochloride, prazosin hydrochloride, ritanserin, tyramine hydrochloride ( $p$-tyramine), $\mathrm{U} 46619$ (9,11-dideoxy-9 $\alpha, 11 \alpha$-epoxymethanoprostaglandin $\mathrm{F}_{2 \alpha \alpha}$ ) (Sigma-Aldrich, Poole, Dorset, UK), ICI-118,551 hydrochloride 
((土)-1-(2,3-(dihydro-7-methyl-1H-inden-4-yl)oxy(-3-((1-methylethyl) amino(-2-butanol hydrochloride) (Tocris Bioscience, Bristol, UK) and phentolamine mesylate (Rogitine ${ }^{\circledR}$; Alliance Pharmaceuticals, Chippenham, Wilts, UK).

All chemicals for the Krebs bicarbonate buffer were of analytical grade and were obtained from Fisher Scientific (Loughborough, Leics, UK) unless otherwise stated. All drugs were dissolved in distilled water, except for prazosin, ICI-118,551 and U46619, which were dissolved in dimethyl sulfoxide and ritanserin which was dissolved in alcohol. Neither dimethyl sulfoxide nor alcohol at the concentrations employed exerted significant effects on coronary artery or ileum responses, respectively.

\section{Results}

\section{Ileum}

Both guinea-pig and rat electrically stimulated ileum exhibited concentration-related contractions in response to tyramine and $\beta$-PEA (Fig. 1). Tissue sections also contracted to tyramine and $\beta$-PEA without electrical stimulation. In guinea-pig unstimulated ileum, the geometric mean $\mathrm{EC}_{30}$ values for tyramine and $\beta$-PEA were $1.89(95 \%$ CI $0.88,4.06) \times 10^{-4}$ and 6.54 $(95 \%$ CI $3.68,11.6) \times 10^{-4} \mathrm{M}$, respectively, yielding a potency ratio of $0 \cdot 3$. The maximum responses as a percentage of methacholine maximum contraction were 73.0 (SEM 2.0) and 53.9 (SEM 5.9) \%, respectively. In unstimulated guineapig ileum, the corresponding maxima were 78.0 (SEM 2.0) and 58.6 (SEM 1.7$) \%$, respectively. In guinea-pig electrically

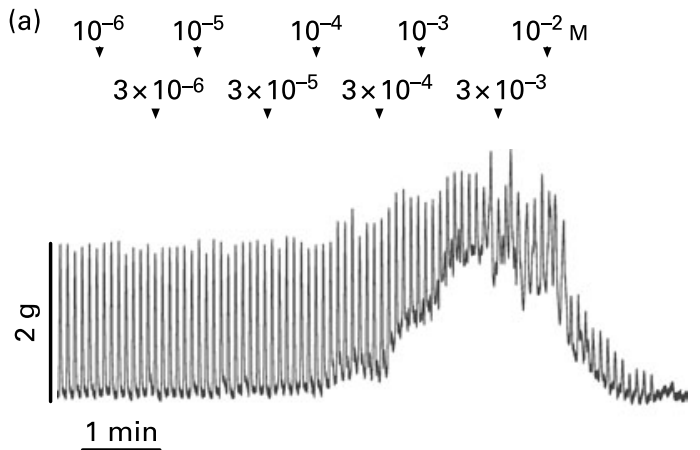

(b)
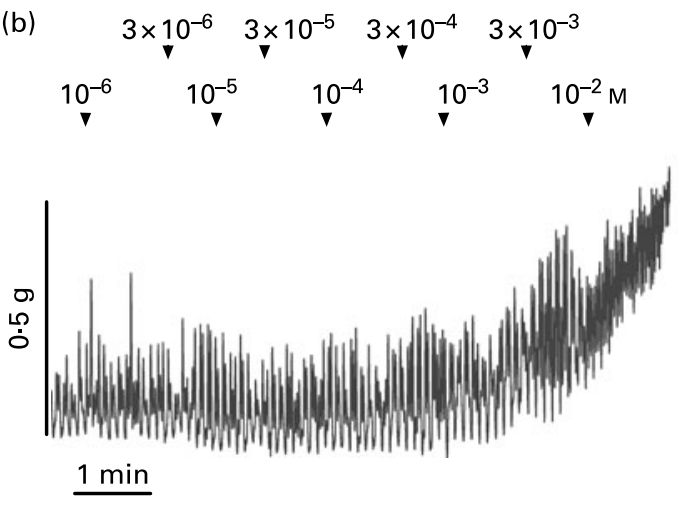

Fig. 1. Typical traces of the contractile effects of $\beta$-phenylethylamine $(\beta-P E A)$ on electrically stimulated guinea-pig (a) and rat $(b)$ isolated intestine. Both show $\beta-P E A$ increasing the baseline tension. stimulated ileum, the non-selective $\alpha$ - and $\beta$-adrenoceptor antagonists phentolamine $\left(10^{-6} \mathrm{M}\right)$ and propranolol $\left(10^{-6}\right.$ M) failed to block the contractions to tyramine (Fig. 2 (a)) or $\beta$-PEA (Fig. 2 (b)). The geometric mean $\mathrm{EC}_{50}$ values for tyramine in unstimulated preparations in the absence $(2.56$ $(95 \%$ CI $1.24,5.20) \times 10^{-4} \mathrm{M}$ or presence of both antagonists $\left(3.48(95 \%\right.$ CI $\left.2.88,4.21) \times 10^{-4} \mathrm{M}\right)$ were not significantly different. Similarly, the $\mathrm{EC}_{50}$ values for $\beta$-PEA in the absence $\left(2.51(95 \%\right.$ CI $\left.1.50,4.20) \times 10^{-4} \mathrm{M}\right)$ or presence of phentolamine $\left(2.51(95 \%\right.$ CI $\left.1.87,3.37) \times 10^{-4} \mathrm{M}\right)$, propranolol $(2.51$ $(95 \%$ CI $\left.2.02,3.13) \times 10^{-4} \mathrm{M}\right)$ and both antagonists $(2.51$ $(95 \%$ CI $\left.1.87,3.37) \times 10^{-4} \mathrm{M}\right)$ did not differ significantly. The increase in baseline tension of guinea-pig electrically stimulated ileum by $\beta$-PEA was not blocked by the non-selective muscarinic acetylcholine receptor antagonist, atropine $\left(10^{-6} \mathrm{M}\right)$, whereas contractions to electrical stimulation were abolished. The $\mathrm{EC}_{50}$ values for $\beta$-PEA in the absence $(5 \cdot 32$ $(95 \%$ CI $\left.1.8,15.3) \times 10^{-4} \mathrm{M}\right)$ or presence of atropine $(3.16$ $(95 \%$ CI $2 \cdot 04,4.91) \times 10^{-4} \mathrm{M} ; n$ 4) did not differ significantly. The $5-\mathrm{HT}_{2 \mathrm{~A} / \mathrm{B} / \mathrm{C}}$ receptor antagonist, ritanserin
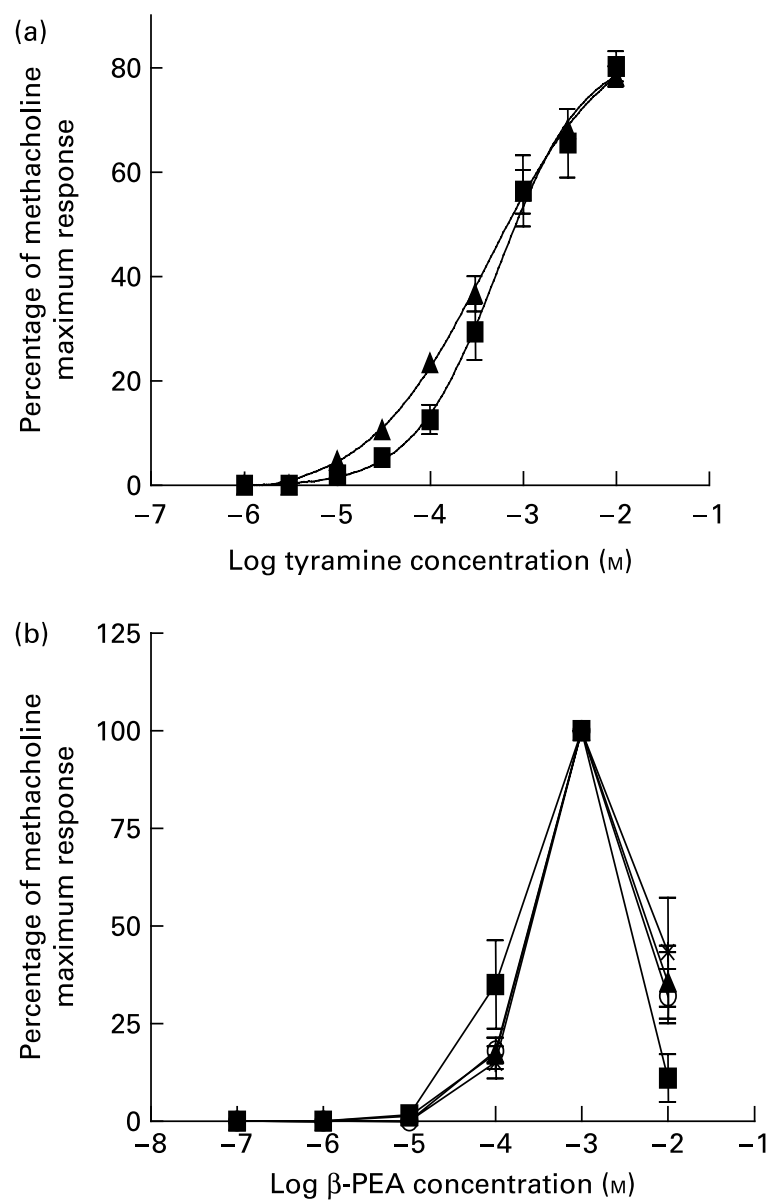

Fig. 2. Concentration-response curves for increases in baseline contractions of guinea-pig electrically stimulated ileum to (a) tyramine and (b) $\beta$-phenylethylamine ( $\beta$-PEA). (a) Tyramine responses plotted as percentages of the maximum response to methacholine (acetyl- $\beta$-methylcholine) in the absence $(\boldsymbol{\Lambda} ; n 7)$ and presence of phentolamine $\left(10^{-6} \mathrm{M}\right)$ and propranolol $\left(10^{-6} \mathrm{M} ; \mathbf{\square}\right.$; $n$ 4). (b) $\beta$-PEA responses plotted as percentages of the maximum response in the absence $(\boldsymbol{\square})$ and presence of phentolamine $\left(10^{-6} \mathrm{M} ; \boldsymbol{\Delta}\right)$, propranolol $\left(10^{-6} \mathrm{M} ; *\right)$ or phentolamine and propranolol $(\diamond)$. Values are means, with standard errors represented by vertical bars. 
$\left(10^{-6} \mathrm{M}\right)^{(19)}$, abolished 5-HT contractions (Fig. 3 (a)) but did not shift the CRC for the contraction of guinea-pig ileum to $\beta$-PEA (Fig. 3 (b)). The $\mathrm{EC}_{50}$ values in the absence $\left(3.16(95 \%\right.$ CI $\left.1.52,6.58) \times 10^{-4} \mathrm{M}\right)$ or presence of ritanserin $\left(5.01(95 \%\right.$ CI $\left.1.16,21.7) \times 10^{-4} \mathrm{M}\right)$ were not significantly different.

\section{Mesenteric vascular bed}

The responses of the vascular bed of the gastrointestinal tract to increasing bolus doses of tyramine and $\beta$-PEA were measured in rat isolated perfused mesenteric beds. Resting perfusion pressure was little affected by tyramine and $\beta$-PEA. However, when perfusion pressure was raised by infusion of the $\alpha$-adrenoceptor agonist, phenylephrine $(100 \mu \mathrm{M})$, tyramine and $\beta$-PEA caused dose-related falls in perfusion pressure indicative of vasodilatation (Fig. 4). The maximum pressure falls were to 84.2 (SEM 4.3) and 59.9 (SEM 5.4) \% of the phenylephrine-induced rise in pressure, respectively.
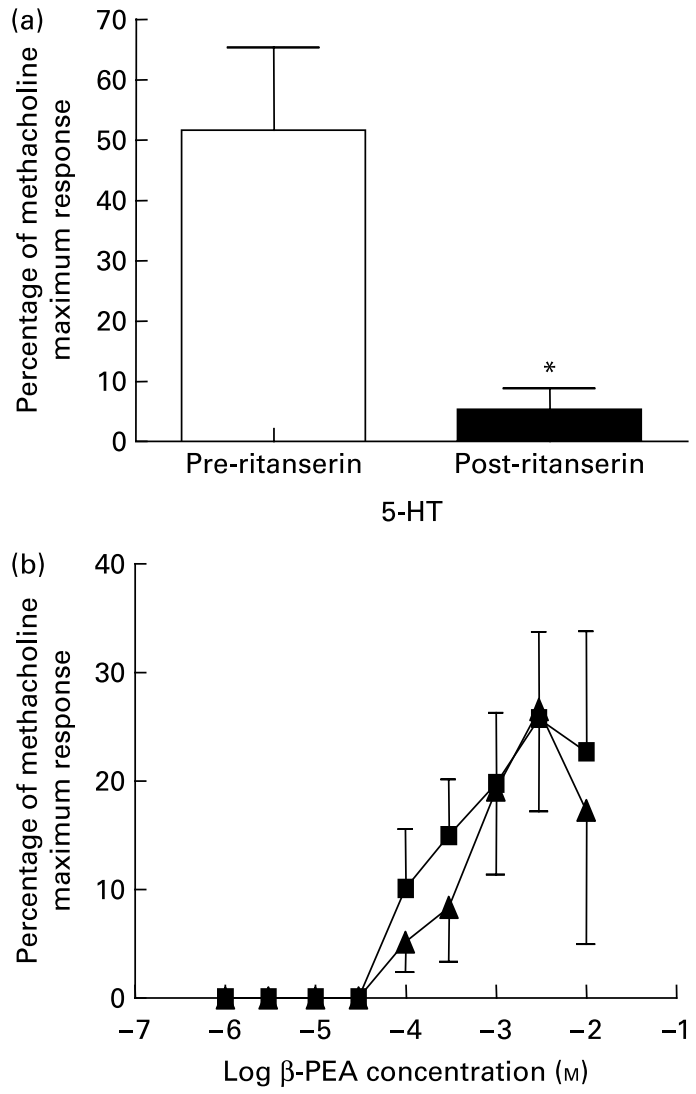

Fig. 3. (a) Baseline contractions of guinea-pig electrically stimulated ileum to 5-hydroxytryptamine $\left(5-\mathrm{HT} ; 3 \times 10^{-6} \mathrm{M}\right)$, plotted as percentages of the maximum response to methacholine (acetyl- $\beta$-methylcholine), before ( $\square$ ) and in the presence of ritanserin $\left(\mathbf{\square} ; 10^{-6} \mathrm{M}\right)$. Values are means, with standard errors represented by vertical bars. * Mean value was significantly different from that pre-ritanserin $(P<0.05)$. (b) Concentration-response curves for increases in baseline contraction of guinea-pig electrically stimulated ileum to $\beta$-phenylethylamine, plotted as percentages of the maximum response to methacholine, in the absence $(\mathbf{\square})$ and presence of ritanserin $\left(10^{-6} \mathrm{M} ; \mathbf{\Delta}\right)$. Values are means $(n 4)$, with standard errors represented by vertical bars.

\section{Aortic rings}

Tyramine and $\beta$-PEA were next examined in guinea-pig and rat isolated aortic ring preparations, from which the endothelium was removed. In contrast to the mesenteric vasculature, $\beta$-PEA and tyramine produced concentration-related vasoconstriction. These responses persisted in the presence of prazosin $(1 \mu \mathrm{M})$, ICI-118,551 $(1 \mu \mathrm{M})$, cocaine $(10 \mu \mathrm{M})$ and pargyline $(10 \mu \mathrm{M})$ to block $\alpha_{1^{-}}$and $\beta_{2}$-adrenoceptors, uptake of sympathomimetic amines and monoamine oxidases $\mathrm{A}$ and B, respectively (Fig. 5). The maximum vasoconstriction to tyramine (62.5 (SEM 23.9) \% of $\mathrm{KCl}$ contraction) was significantly less than to $\beta$-PEA (138.3 (SEM 23.9) \%) in rat aorta. Tyramine could therefore be regarded as a partial agonist.

\section{Pig coronary artery}

To examine a smaller vessel rather than a major conductance vessel such as the aorta, we used isolated rings of pig left anterior descending coronary arteries with intact endothelium. Cumulative CRC to tyramine or $\beta$-PEA were obtained. Tyramine and $\beta$-PEA caused concentration-dependent vasoconstriction (Fig. 6) which reached maxima of 51.0 (SEM 6.6) (n 4) and 74.3 (SEM 9.1) \%, respectively, of the $\mathrm{KCl}$ constriction. These constrictions were not prevented by the $\alpha_{1}$-adrenoceptor antagonist, prazosin (1 $\mu \mathrm{M})$ (Fig. 6).

(a)
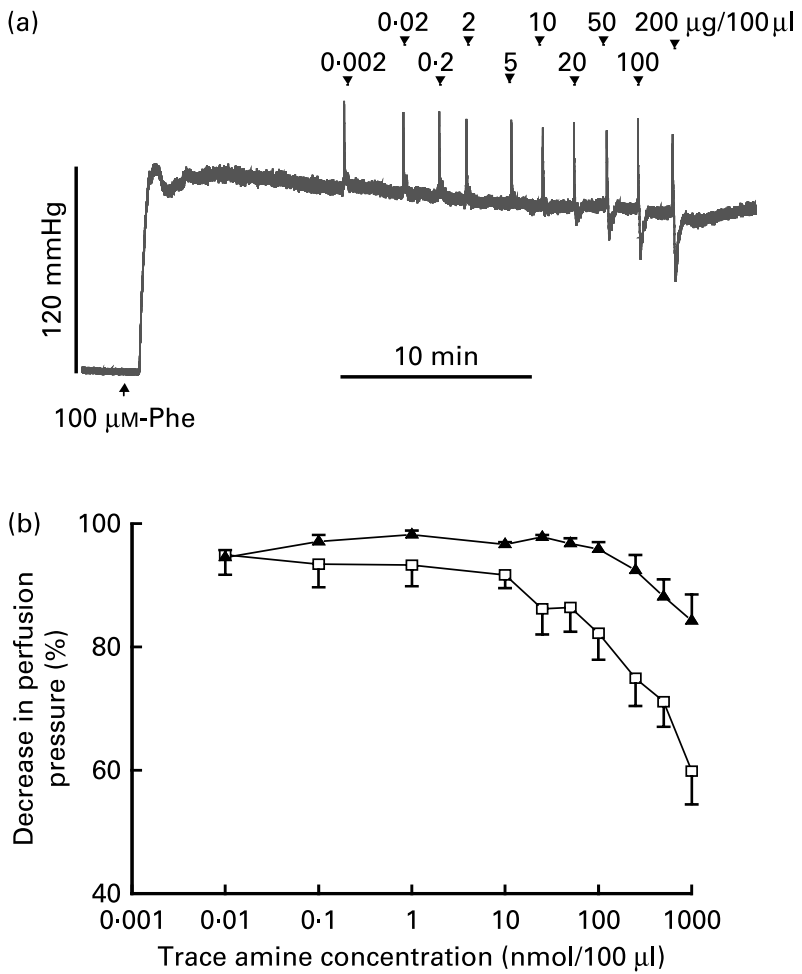

Fig. 4. Vasodilator effects of $\beta$-phenylethylamine ( $\beta$-PEA) and tyramine in rat isolated perfused mesenteric vascular beds. (a) Typical trace for falls in perfusion pressure of the mesenteric bed with increasing doses of $\beta$-PEA with resting perfusion pressure raised by infusion of phenylephrine (Phe, $100 \mu \mathrm{M}$ ). The initial spike increases in pressure are injection artifacts. (b) Doseresponse curves for falls in mesenteric vascular pressure to tyramine $(\boldsymbol{\Lambda} ; n 4)$ and $\beta$-PEA ( $\square n 4$ ), plotted as percentages of the increase in pressure by Phe against concentration $(\mu \mathrm{g} / 100 \mu \mathrm{l})$. Values are means, with standard errors represented by vertical bars. 

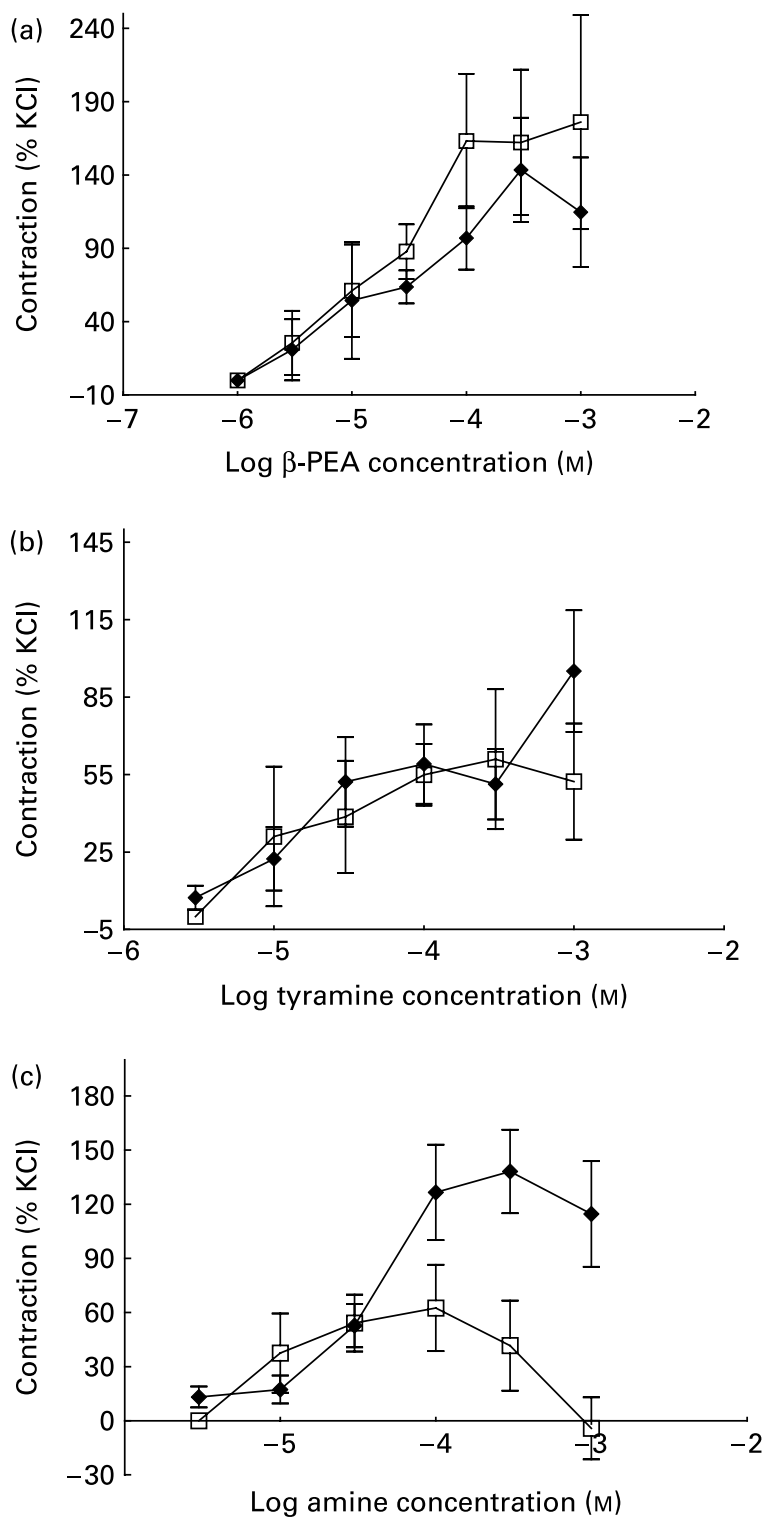

Fig. 5. Vasoconstrictor effects of $\beta$-phenylethylamine ( $\beta$-PEA) and tyramine in rat and guinea-pig isolated aortic rings. (a) Concentration-response curves (CRC) for constriction of guinea-pig aortic rings by $\beta$-PEA in the absence $(\square)$ and presence of the inhibitors prazosin $(1 \mu \mathrm{M}), \mathrm{ICl}-118,551$ $(1 \mu \mathrm{M})$, cocaine $(10 \mu \mathrm{M})$ and pargyline $(10 \mu \mathrm{M})(\diamond)$. Values are means $(n 6)$, with standard errors represented by vertical bars. (b) CRC for the constriction of guinea-pig aortic rings by tyramine in the absence $(\square)$ and presence of the inhibitors $(\bullet)$. Values are means $(n 5)$, with standard errors represented by vertical bars. (c) CRC for the constriction of rat aortic rings by tyramine $(\square n 4)$ and $\beta$-PEA $(\bullet ; 6)$ in the presence of the inhibitors. Values are means, with standard errors represented by vertical bars.

\section{Discussion}

Tyramine and $\beta$-PEA contracted both guinea-pig and rat isolated gut preparations. In the guinea-pig ileum, tyramine consistently produced a greater maximum response (relative to the methacholine maximum contraction) than $\beta$-PEA, whether in electrically stimulated or unstimulated tissues. These responses were not inhibited by antagonists of the major neurotransmitters of the gut, namely noradrenaline, acetylcholine and 5-HT via adrenoceptors, muscarinic receptors and $5-\mathrm{HT}_{2}$ receptors, respectively. A contractile response of the gut is opposite to that expected of sympathomimetic amines, such as noradrenaline and adrenaline, which relax the gastrointestinal tract ${ }^{(20,21)}$. The relaxation is due to direct activation of $\beta_{1^{-}}$and $\alpha_{1}$-adrenoceptors on the longitudinal smooth muscle ${ }^{(22)}$. Indirect sympathomimetic amines such as tyramine have also been shown to reduce myogenic activity of rabbit ileum, an effect attributed to the release of noradrenaline from sympathetic neurones in the gastrointestinal wall ${ }^{(23)}$. However, the more usual response reported in the literature has been a contraction to tyramine and $\beta$-PEA of guinea-pig ileum $^{(24)}$ and rabbit jejunum ${ }^{(21,25)}$, an effect that unlike the present findings was attributed to stimulation of 5-HT receptors ${ }^{(24,25)}$. However, in these relatively old studies, the selectivity of available antagonists was poor. Furthermore, it was found that desensitisation of 5-HT receptors by prolonged exposure to 5-HT abolished the contractions to 5-HT but not $\beta$-PEA ${ }^{(25)}$, suggesting that $\beta$-PEA was not operating through 5-HT receptors.

These results have therefore shown that tyramine and $\beta$-PEA contract rather than relax the gut, a response that is inconsistent with a sympathomimetic action. Furthermore, the response is not abolished by antagonists of muscarinic or 5-HT receptors that are known to mediate contraction of the gut. Similarly, the vasoconstrictor actions of tyramine and $\beta$-PEA in rat and guinea-pig aortic and pig coronary blood vessels were resistant to adrenoceptor blockade. Therefore the vasoconstriction remaining in the presence of these antagonists was not due to noradrenaline release from sympathetic neurones in the aortic wall. Therefore $\beta$-PEA and tyramine were not behaving as indirect sympathomimetic amines by acting. In contrast to the aorta and coronary arteries, tyramine and $\beta$-PEA failed to constrict the mesenteric blood vessels supplying the gastrointestinal tract. Instead, when the pressure was raised by infusing phenylephrine, there was vasodilatation.

The present results overturn the dogma that has persisted for over 30 years that these amines owe their pharmacological actions to indirect sympathomimetic properties. They can clearly exert contractile effects on the gut and blood vessels via an alternative and hitherto unidentified pathway. Trace amines have been shown to bind to receptors now called TAA receptors ${ }^{(16,17,26)}$. These receptors were identified by the selection of oligonucleotide sequences based on G-proteincoupled receptors for serotonin ${ }^{(14)}$ or dopamine ${ }^{(15)}$ and amplification by PCR of novel DNA sequences. Cell lines were then transfected with the cloned sequences resulting in novel orphan receptors coupled to cAMP production. Several TAA receptors have now been cloned but only TAA receptors 1 and 4 are contenders for a functional role since only these recognise tyramine or $\beta$-PEA ${ }^{(16,26)}$. We therefore propose that tyramine and $\beta$-PEA exert their non-adrenergic responses via trace amine receptors. Human embryonic kidney (HEK293) cells stably expressing rat TAA 1 receptors show tyramine to be more potent than $\beta$-PEA for cAMP accumulation by potency ratios of $0.23^{(17)}$ or $0 \cdot 29^{(15)}$. The TAA receptor 4 receptor expressed in COS-7 cells shows stimulation of cAMP for which $\beta$-PEA is $8 \cdot 9-$ fold $^{(26)}$ more potent than tyramine. In the present studies, the potency ratios were 0.62 $\left(\mathrm{EC}_{50}\right.$ ratio) in pig coronary artery, $0.13\left(\mathrm{EC}_{50}\right.$ ratio in the presence of antagonists) in guinea-pig aorta and $0.30\left(\mathrm{EC}_{30}\right.$ ratio in the presence of propranolol and phentolamine) in the unstimulated guinea-pig ileum. Tyramine was therefore marginally 
(a)

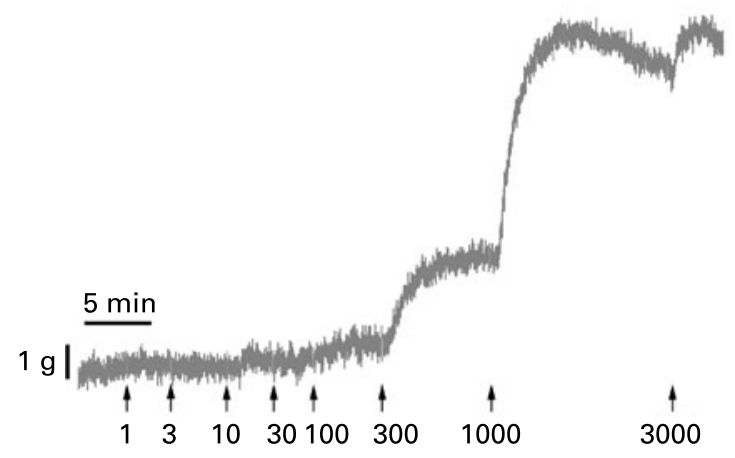

(b)

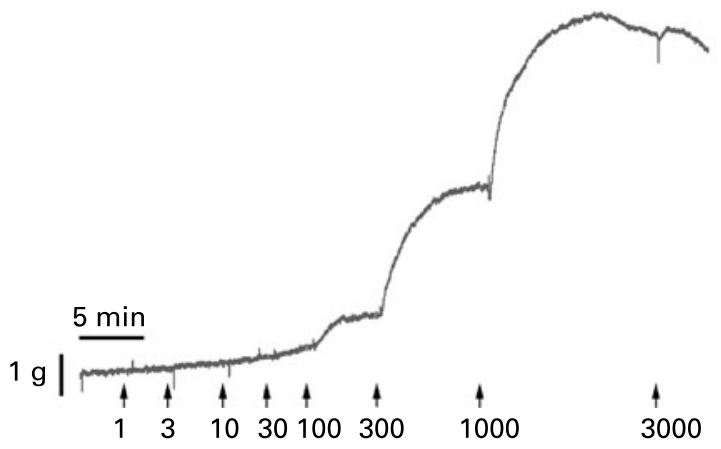

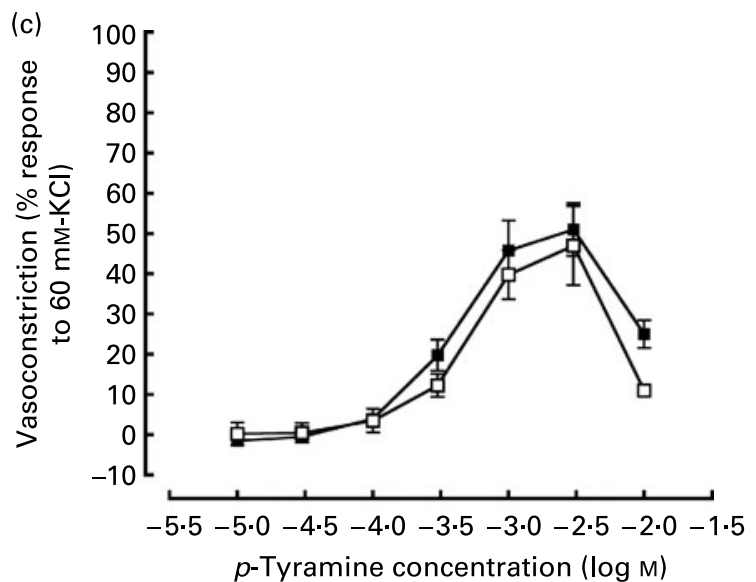

(d)

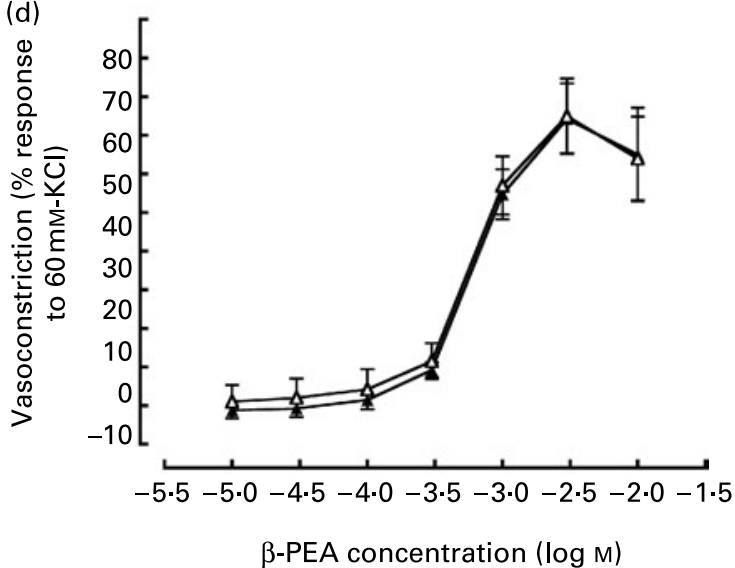

Fig. 6. Vasoconstrictor effects of $\beta$-phenylethylamine ( $\beta-P E A)$ and tyramine in isolated rings from pig left anterior descending coronary artery. (a) Typical trace for a concentration-response curve (CRC) for the constrictor response to $\beta$-PEA. (b) Typical trace for a CRC for the constrictor response to $\beta$-PEA in the presence of prazosin $(1 \mu \mathrm{M})$. (c) CRC for tyramine in the absence $(\square)$ and presence of prazosin $(\square ; 1 \mu \mathrm{M})$. Values are means $(n 4)$, with standard errors represented by vertical bars. (d) CRC for $\beta$-PEA in the absence $(\mathbf{\Lambda})$ and presence of prazosin $(\Delta ; 1 \mu \mathrm{M})$. Values are means $(n)$ ), with standard errors represented by vertical bars.

more potent than $\beta$-PEA, suggesting a role for TAA receptor 1 . However, in the rat aorta tyramine was a weak partial agonist, which, assuming that it interacts with the same receptor as $\beta$-PEA, does not support the contention of TAA receptor 1 involvement. Furthermore, the contractile responses observed here are clearly not due to cAMP generation which would relax smooth muscle ${ }^{(20)}$. Further work is necessary to characterise the receptors involved in these native tissues and a major breakthrough would be the identification of a selective antagonist which is currently unavailable.

Concentrations of tyramine and $\beta$-PEA in the circulation comparable with those revealing effects on the gut and vasculature could be achieved by a number of means. Pressor responses are typically associated with a high dietary intake of tyramine, especially in individuals taking monoamine oxidase inhibitors to prevent its degradation in the intestine before reaching the circulation ${ }^{(26)}$, in smokers who have lower monoamine oxidase A and B levels ${ }^{(27)}$ and in women taking isoflavones as an alternative to hormone replacement therapy ${ }^{(28)}$. Plasma levels of tyramine are also elevated in hypertensive patients ${ }^{(29)}$ and in patients with migraine headaches ${ }^{(30)}$. Pressor responses are induced by the oral administration of doses of tyramine in the range $100-200 \mathrm{mg}$ and the oral dose of tyramine to produce a $30 \mathrm{mmHg}$ rise in systolic blood pressure is approximately $7 \mathrm{mg} / \mathrm{kg}(500 \mathrm{mg}$ in a $70 \mathrm{~kg}$ subject) ${ }^{(31)}$. Tyramine concentrations able to induce pressor responses can reach these levels in many fermented foods such as sausages $(>200 \mathrm{mg} / \mathrm{kg})^{(32)}$ and goat $(2000 \mathrm{mg} / \mathrm{kg})^{(33)}$ and Dutch cheese $(300 \mathrm{mg} / \mathrm{kg})^{(34)}$. The concentrations of tyramine in the gut will be higher than in the circulation and in the range capable of stimulating the gut found in the present study.

From the present results we can hypothesise that trace amines, such as tyramine and $\beta$-PEA, found in the diet may have a physiological role in mammalian digestion. After ingestion, they stimulate the gut thereby facilitating digestion. The concomitant vasodilatation of the mesenteric vascular bed and increased blood flow to the gastrointestinal tract would provide energy to support the enhanced gut motility and release of digestive enzymes, and assist transport of absorbed nutrients from the gut ${ }^{(35)}$. Increases in visceral blood supply are met by a compensatory restriction of blood supply to some other organs ${ }^{(35)}$. The vasoconstrictor effects of tyramine and $\beta$-PEA on blood vessels other than those of the mesentery are demonstrated by the vasoconstriction observed here in the aorta and coronary arteries. Thus, the relief of bloating ${ }^{(6)}$ and increased transit through the gut $^{(36)}$ 
that has been reported for probiotics could be due to increased gut activity by the generation of trace amines by their content of Lactobacillus, Lactococcus and Enterococcus species. Our hypothesis could also apply to other foods such as cocoa products, cheeses, sausages and red wine, which are often eaten before or after meals in the belief that they aid digestion. Our hypothesis will require verification in vivo to show that the effects of trace amines seen here in vitro can be extended to their oral administration, and reproduced after ingestion of trace amine-rich foods.

\section{Acknowledgements}

There are no conflicts of interest for any of the authors of the study.

The study was supported by grants from the British Heart Foundation and a Wellcome Trust Fellowship (to M. A. A.).

K. J. B. wrote the manuscript and interpreted the data; M. A. A. performed the mesenteric vasculature studies; A. A. H. performed the pig coronary artery studies; M. F. performed the rat aorta studies; E. M. J. and W. E. D. performed the ileum studies; E. J. K. designed and interpreted the rat aorta studies; W. R. F. designed and interpreted the ileum studies.

\section{References}

1. Burchett SA \& Hicks TP (2006) The mysterious trace amines: protean neuromodulators of synaptic transmission in mammalian brain. Prog Neurobiol 79, 223-246.

2. Branchek TA \& Blackburn TP (2003) Trace amine receptors as targets for novel therapeutics: legend, myth and fact. Curr Opin Pharmacol 3, 90-97.

3. Taylor CJ \& Mahenthralingham E (2006) Functional foods and paediatric gastro-intestinal health and disease. Ann Trop Paediatrics 26, 79-85.

4. Fedorak RN \& Madsen KL (2004) Probiotics and prebiotics in gastrointestinal disorders. Curr Opin Gastroenterol 20, 146-155.

5. Houghton LA \& Whorwell PJ (2005) Towards a better understanding of abdominal bloating and distension in functional gastrointestinal disorders. Neurogastroenterol Motil 17, 500-511.

6. Kim HJ, Camilleri M, McKinzie S, et al. (2003) A randomized controlled trial of a probiotic, VSL 3, on gut transit and symptoms in diarrhoea-predominant irritable bowel syndrome. Aliment Pharmacol Ther 17, 895-904.

7. Nobaek S, Johansson ML, Molin G, et al. (2000) Alteration of intestinal microflora is associated with reduction in abdominal bloating and pain in patients with irritable bowel syndrome. Am J Gastroenterol 95, 1231-1238.

8. Kim HJ, Vazquez Roque MI, Camilleri M, et al. (2005) A randomized controlled trial of probiotic combination VSL 3 and placebo in irritable bowel syndrome. Neurogastroenterol Motil 17, 687-696.

9. Marcobal A, de la Rivas B \& Muñoz R (2006) First genetic characterization of a bacterial (-phenylethylamine biosynthetic enzyme in Enterococcus faecium RM58. FEMS Microbiol Lett 258, 144-149.

10. Trendelenburg U (1972) Classification of sympathomimetic amines. In Catecholamines. Handbook of Experimental Pharmacology, vol. 33, pp. 336-362 [H Blascho and E Muscholl, editors]. Berlin: Springer-Verlag.
11. Fehler M, Broadley K \& Kidd E (2006) Contraction of rat isolated aorta to $\beta$-phenylethylamine not mediated by adrenoceptors. Proc Br Pharmacol Soc $\mathrm{pA}_{2}$ online 4, 2, 182P.

12. Herbert AA \& Broadley KJ (2006) Action of trace amine $p$-tyramine on adrenergic receptors in isolated porcine coronary artery, Proc Br Pharmacol Soc $\mathrm{pA}_{2}$ online 4 issue, 2, 104P http://www. pa2online.org/abstracts/2Vol4Issue2abst104P.pdf

13. Baker KE, Herbert AA \& Broadley KJ (2007) Vasoconstriction of porcine left anterior descending coronary artery by ecstasy and cathinone is not an indirect sympathomimetic effect. Vasc Pharmacol 47, 10-17.

14. Borowsky B, Adham N, Jones KA, et al. (2001) Trace amines: identification of a family of mammalian $\mathrm{G}$ protein-coupled receptors. Proc Natl Acad Sci U S A 98, 8966-8971.

15. Bunzow JR, Sonders MS, Arttamangkul S, et al. (2001) Amphetamine 3,4-methylenedioxymethamphetamine, lysergic acid diethylamine, and metabolites of the catecholamine neurotransmitters are agonists of a rat trace amine receptor. $\mathrm{Mol}$ Pharmacol 60, 1181-1188.

16. Lindemann L \& Hoener MCA (2005) renaissance in trace amines inspired by a novel GPCR family. Trends Pharmacol Sci 26, 274-281.

17. Lindemann L, Ebeling M, Kratochwil NA, et al. (2005) Trace amine-associated receptors form structurally and functionally distinct subfamilies of novel $\mathrm{G}$ protein-coupled receptors. Genomics 85, 372-385.

18. Meyers PR, Banitt PF, Guerra R Jr, et al. (1991) Role of endothelium in modulation of the acetylcholine vasoconstrictor response in porcine coronary microvessels. Cardiovasc Res 25, 129-137.

19. Hoyer D, Clarke DE, Fozard JR, et al. (1994) International union of pharmacology classification of receptors for 5hydroxytryptamine (serotonin). Pharmacol Rev 46, 157-203.

20. Broadley KJ (1996) Autonomic Pharmacology. London: Taylor and Francis.

21. Van Rossum JM \& Mujić M (1965) Classification of sympathomimetic drugs on the rabbit intestine. Arch Int Pharmacodyn Ther 155, 418-431.

22. Broadley KJ \& Grassby PF (1985) Alpha- and beta-adrenoceptor-mediated responses of the guinea-pig ileum and the effects of neuronal uptake inhibition. Naunyn-Schmiedebergs Arch Pharmacol 331, 316-323.

23. Schmidt JL \& Fleming WW (1963) The structure of sympathomimetics as related to reserpine induced sensitivity changes in the rabbit ileum. J Pharmacol Exp Ther 139, $230-237$

24. Jamieson DD \& Taylor KM (1979) Non-specific stimulant activity of tyramine on isolated intestinal preparations. Agents Actions 9, 422-427.

25. Innes IR \& Kohli JD (1969) Excitatory action of sympathomimetic amines on 5-hydroxytryptamine receptors of gut. $\mathrm{Br} J$ Pharmacol 35, 383-393.

26. Zucchi R, Chiellini G, Scanlan TS, et al. (2006) Trace amineassociated receptors and their ligands. Br J Pharmacol 149, 967-978

27. Berlin I \& Anthenelli RM (2001) Monoamine oxidases and tobacco smoking. Int J Neuropsychopharmacol 4, 33-42.

28. Hutchins AM, McIver IE \& Johnston CS (2005) Hypertensive crisis associated with high dose soya isoflavone supplementation in a post-menopausal woman: a case report [ISRCTN98074661]. BMC Womens Health 5, 1-5.

29. Andrew R, Best SA, Watson DG, et al. (1993) Analysis of biogenic amines in plasma of hypertensive patients and a control group. Neurochem Res 18, 1179-1182.

30. D'Andrea G, Terrazzino S, Leon A, et al. (2004) Elevated levels of circulating trace amines in primary headaches. Neurology $\mathbf{6 2}$, $1701-1705$. 
31. Peatfield R, Littlewood JT, Glover V, et al. (1983) Pressor sensitivity to tyramine in patients with headache: relationship to platelet monoamine oxidase and to dietary provocation. J Neurol Neurosurg Psych 46, 827-831.

32. Suzzi G \& Gardini F (2003) Biogenic amines in dry fermented sausages: a review. Int J Food Microbiol 88, 41-54.

33. Bonetta S, Bonetta S, Carraro E, et al. (2008) Detection of biogenic amine producer bacteria in a typical Italian goat cheese. J Food Prot 71, 205-209.
34. Komprda T, Burdychova R, Dohnal V, et al. (2008) Tyramine production in Dutch-type semi-hard cheese from two different producers. Food Microbiol 25, 219-227.

35. Chou CC (1983) Splanchnic and overall cardiovascular hemodynamics during eating and digestion. Fed Proc 42, 1658-1683.

36. Niedzielin K, Kordecki H \& Birkenfield B (2001) A controlled, double-blind, randomized study on the efficacy of Lactobacilus plantarum $299 \mathrm{~V}$ in patients with irritable bowel syndrome. Eur J Gastroenterol Hepatol 13, 1143-1147. 